\title{
Effects of an isolated or enriched environment after handling on sexual maturation and behaviour in male and female rats
}

\author{
Heidi H. Swanson and N. E. van de Poll \\ Netherlands Institute for Brain Research, IJdijk 28, 1095 KJ Amsterdam, The Netherlands
}

\begin{abstract}
Summary. Male and female rats that were handled from birth to 30 days had increased adrenal weight at weaning. The animals were then rehoused in (a) groups of 10 in a large cage with an enriched environment, (b) a small cage in pairs, or (c) a small cage alone. Isolation advanced and enrichment retarded vaginal opening (in comparison with paired animals) in handled and unhandled females. Puberty was accelerated by handling irrespective of housing conditions. Isolation improved sexual performance in male rats: almost all ejaculated within 4 daily testing sessions with a receptive female, whereas only half the pair-housed males and even fewer group-housed animals copulated. The group-housed copulators were sexually the most active in a hierarchy observed when a single receptive female was placed in the enriched cage for $15 \mathrm{~min}$. The rank order in which these males initiated and consummated sexual activity was consistent over several tests.
\end{abstract}

\section{Introduction}

Male rats require a certain amount of sexual experience before they execute a complete copulatory sequence, in contrast to females which, provided that they are in proper hormonal condition and receive adequate stimulation, spontaneously show lordosis and receptive behaviour. Isolation after weaning may result in aberrant copulatory behaviour in male rats, characterized by unco-ordinated attempts to mount the female from the head or side and failure to achieve intromission and ejaculation (Gerall, Ward \& Gerall, 1967; Duffy \& Hendricks, 1973; Spevak, Quadagno, Knoeppel \& Poggio, 1973). This has been attributed to lack of opportunity to practice copulatory behaviour which is a prominent element of prepubertal play (Hård \& Larsson, 1968, 1971).

Handled animals are reported to react to stressful experience in a more adaptive manner, being more active and exploratory and less emotional in a novel situation. Other effects associated with early handling are faster growth, earlier eye-opening and sexual maturation (DeNelsky \& Denenberg, 1967; Levine, Haltmeyer, Karas \& Denenberg, 1967; Levine \& Thoman, 1970; Villescas, Zamenhof \& Guthrie, 1979). On the other hand, housing in groups has been reported to delay sexual maturation in many species of rodents including rats (Hansen, Larsson, Carlsson \& Sourander, 1978; Swanson, McConnell, Uylings, Van Oyen \& van de Poll, 1983). In the present experiments the interaction of pre-weaning handling and post-weaning differential housing on sexual maturation was examined. 


\section{Materials and Methods}

Handling. Young Wistar rats were mixed on the day of birth to produce litters containing 4 males and 4 females. 'Handled' young were alternated daily between two lactating mothers until the age of 30 days. Every morning, after having been marked with a felt pen for identification and weighed, the young from two litters were interchanged. In the evening they were returned to their original mother. 'Unhandled' young were not weighed and were left with one lactating mother throughout. At 30 days 8 handled and 8 unhandled rats of each sex were killed, and body, brain and adrenal weights were taken. This whole procedure was similar to that used for underfed young in previous experiments (Swanson et al., 1983).

Enrichment of environment. The remaining animals were assigned to three types of housing condition.

(1) Handled-enriched (Group HE) and unhandled-enriched (Group UE) animals of each sex were placed in groups of 10 in large cages $(75 \times 75 \times 85 \mathrm{~cm})$ constructed of wire mesh with a glass front, containing ladders, ropes, tubes and other toys. The objects were rearranged weekly when the cages were cleaned. The 4 enriched cages therefore contained 10 handled males, 10 handled females, 10 unhandled males and 10 unhandled females.

(2) Animals of similar sex were paired in normal laboratory cages $(35 \times 23 \times 15 \mathrm{~cm})$ made of translucent plastic to give 5 cages of handled (Group HP) and 5 cages of unhandled (Group UP) rats of each sex.

(3) Rats were housed singly in cages of the type used for Groups HP and UP to give 10 cages of handled (Group HI) and 10 cages of unhandled (Group UI) rats of each sex.

Females were examined daily for vaginal opening.

Social behaviour in enriched cages. When the rats were 5-7 weeks old, daily observations were made under red light during the dark period. Each cage was observed for $5 \mathrm{~min}$ and a record was kept of which individuals (marked with black hair dye for identification) started wrestling bouts, held down or chased their opponent. The recipients of this aggressive play were also identified. Observations were repeated at intervals 2-3 times per day, for a total of 14 sessions.

Male sexual behaviour. Two procedures were used for testing sexual behaviour in males at 100 days of age. To ascertain the existence of a possible sexual hierarchy, a single receptive female was introduced into each enriched cage of 10 males and the behaviour of the males was observed for 15 min. The order in which individual males mounted the stimulus female and ejaculated was recorded. The test was repeated $1 \mathrm{~h}$ later with another female. This procedure was carried out on 3 consecutive days. The following week all males (also pairs and isolated) were tested individually for sexual behaviour with a receptive female for $30 \mathrm{~min}$.

\section{Results}

Body and organ weights at 30 days (Table 1)

There was no significant difference in body or brain weight attributable to sex or handling. Organ weights were therefore expressed and analysed as absolute values. There was no sex difference in adrenal weights in these pre-pubertal animals, but adrenals were significantly heavier in handled animals of both sexes.

\section{Vaginal opening}

Handling advanced and enrichment delayed sexual maturation in females (Text-fig. 1). There was no interaction. In Group HI the first female had vaginal opening at 33 days and the last at 43 days, in contrast to Group UE in which first opening occurred at 37 days and the last at 58 days. There was no significant difference between groups in body weight at the time of vaginal opening (Table 2). 
Table 1. Body and organ weights of rats weaned at 30 days of age

\begin{tabular}{|c|c|c|c|c|c|c|c|c|}
\hline \multirow[b]{2}{*}{ Weight } & \multicolumn{4}{|c|}{ Males } & \multicolumn{4}{|c|}{ Females } \\
\hline & Handled & $\begin{array}{c}\text { Not } \\
\text { handled }\end{array}$ & $\underset{\mathrm{df}(1,14)}{\mathbf{F}}$ & $P$ & Handled & $\begin{array}{c}\text { Not } \\
\text { handled }\end{array}$ & $\underset{\operatorname{df}(1,14)}{F}$ & $P$ \\
\hline Body (g) & 63 & 57 & 1.95 & NS & 62 & 53 & $4 \cdot 50$ & NS \\
\hline Brain (mg) & 1432 & 1400 & 1.50 & NS & 1380 & 1357 & 1.00 & NS \\
\hline Adrenals (mg) & 19.4 & $14 \cdot 5$ & 16.03 & $<0.01$ & 18.9 & 14.0 & $12 \cdot 47$ & $<0.01$ \\
\hline
\end{tabular}

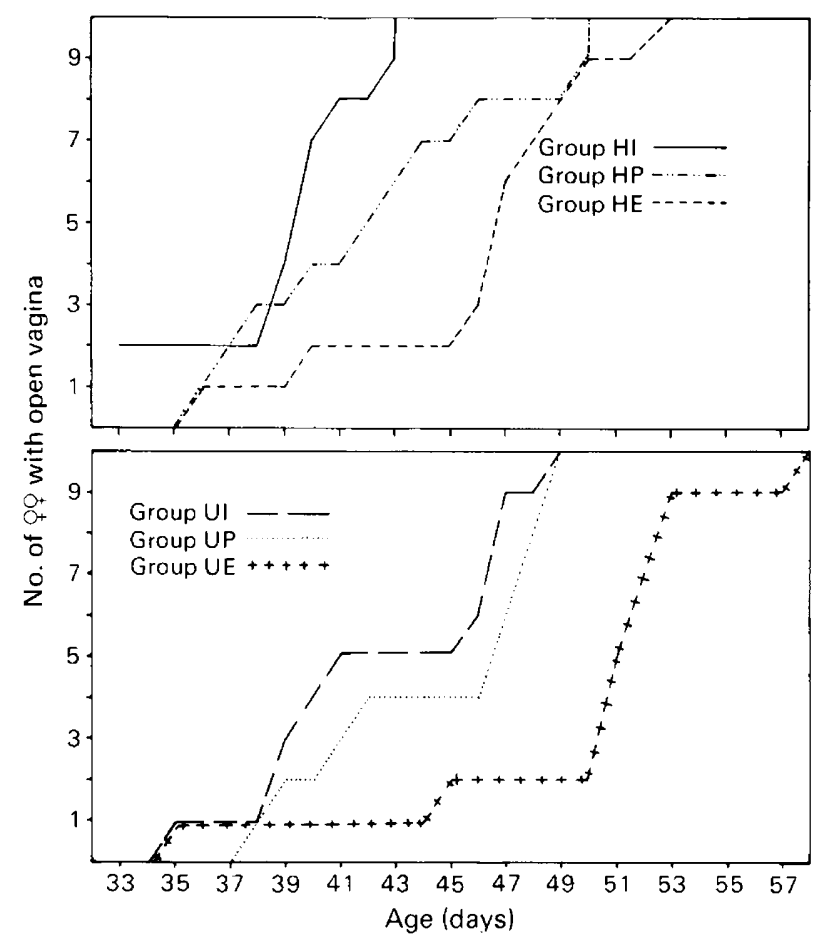

Text-fig. 1. Ages at vaginal opening of handled (Groups HI, HP and HE) and unhandled (Groups UI, UP and UE) rats housed alone (Groups HI and UI), in pairs (Groups HP and UP) or in groups of 10 (Groups HE and UE).

Table 2. Age and weight of rats at vaginal opening

\begin{tabular}{|c|c|c|c|c|c|c|c|c|c|c|}
\hline & \multirow{3}{*}{$\begin{array}{c}\text { Group } \\
\text { HE }\end{array}$} & \multirow{3}{*}{$\begin{array}{c}\text { Group } \\
\text { HP }\end{array}$} & \multirow{3}{*}{$\begin{array}{c}\text { Group } \\
\text { HI }\end{array}$} & \multirow{3}{*}{$\begin{array}{l}\text { Group } \\
\text { UE }\end{array}$} & \multirow{3}{*}{$\begin{array}{l}\text { Group } \\
\text { UP }\end{array}$} & \multirow{3}{*}{$\begin{array}{c}\text { Group } \\
\text { UI }\end{array}$} & \multicolumn{4}{|c|}{ Analysis of variance } \\
\hline & & & & & & & \multicolumn{2}{|c|}{ Handling } & \multicolumn{2}{|c|}{ Environment } \\
\hline & & & & & & & $F(1,54)$ & $P$ & $F(2,54)$ & $P$ \\
\hline Age (days) & $\begin{array}{l}44 \cdot 3 \\
\pm 1 \cdot 4\end{array}$ & $\begin{array}{l}40 \cdot 4 \\
\quad \pm 2.3\end{array}$ & $\begin{array}{l}38.9 \\
\quad \pm 0.7\end{array}$ & $\begin{array}{l}48.9 \\
\quad \pm 1.9\end{array}$ & $\begin{array}{l}43.6 \\
\pm 1.5\end{array}$ & $\begin{array}{l}42 \cdot 2 \\
\pm 1.4\end{array}$ & 8.99 & $<0.01$ & 8.89 & $<0.001$ \\
\hline Body wt (g) & $\begin{array}{l}105 \\
\pm 3.2\end{array}$ & $\begin{array}{l}91 \\
\pm 5.8\end{array}$ & $\begin{array}{l}97 \\
\pm 2 \cdot 2\end{array}$ & $\begin{array}{l}92 \\
\pm 2 \cdot 3\end{array}$ & $\begin{array}{l}94 \\
\pm 4 \cdot 2\end{array}$ & $\begin{array}{l}94 \\
\pm 5 \cdot 4\end{array}$ & $1 \cdot 21$ & NS & 1.52 & NS \\
\hline
\end{tabular}


Social behaviour in enriched cages

Although all animals frequently engaged in play fighting, 1 or 2 individual males (handled or unhandled) consistently initiated most wrestling bouts, held down or chased their opponent. There was no clear hierarchy amongst the rest, either as initiators or recipients of aggressive play. Females showed similar play patterns, but these activities were started by different individuals.

\section{Male sexual behaviour}

Group tests. When a receptive female was introduced into a large cage containing 10 males, only a few showed sexual interest and immediately started to sniff, follow and mount the female who responded with lordosis. Between mounts the female ran away, and was chased by the active males, so that there was a chain of 2 or 3 males all following the female. Only the first 1 or 2 males managed to mount the female with sufficient frequency to reach ejaculation. The mating hierarchy was very constant, in that the rank order in which the males first initiated sexual contact and ejaculated hardly varied in 6 tests carried out over 3 days (Table 3). Only 3 handled and 4 unhandled males ejaculated at all, and of these only 2 in each group did so consistently. The other males in the cage remained completely oblivious to the female. In each of Groups $\mathrm{HE}$ and UE, the sexually most active male was the same individual who started the most play fights as a juvenile.

Table 3. Incidence of copulators amongst male rats in Groups HE and UE at 100 days of age

\begin{tabular}{|c|c|c|c|c|c|}
\hline \multirow[b]{3}{*}{ Animal } & \multirow{2}{*}{\multicolumn{2}{|c|}{ Rank order }} & \multicolumn{3}{|c|}{$\begin{array}{l}\text { No. of tests in which individuals } \\
\text { showed sexual behaviour }\end{array}$} \\
\hline & & & \multicolumn{2}{|c|}{ Enriched cage } & \multirow{2}{*}{$\frac{\text { Individual cage }}{\text { Ejaculated }}$} \\
\hline & $\begin{array}{l}\text { Play-fighting } \\
\text { at } 35 \text { days }\end{array}$ & $\begin{array}{c}\text { Sexual } \\
\text { hierarchy } \\
\text { at } 100 \text { days }\end{array}$ & $\begin{array}{l}\text { First to } \\
\text { mount }\end{array}$ & Ejaculated & \\
\hline \multicolumn{6}{|l|}{ Group HE } \\
\hline A & 1st & $1 \mathrm{st}$ & 6 & 6 & 4 \\
\hline B & - & 2nd & - & 4 & 4 \\
\hline $\mathrm{C}$ & - & 3 rd & - & 1 & 3 \\
\hline $\mathrm{D}$ & - & - & - & - & 3 \\
\hline $\mathbf{E}$ & 2nd & - & - & - & 3 \\
\hline $\bar{F}$ & - & - & - & - & 2 \\
\hline G & - & - & - & - & - \\
\hline $\mathbf{H}$ & - & - & - & - & - \\
\hline I & - & - & - & - & - \\
\hline $\mathbf{J}$ & - & - & - & - & - \\
\hline \multicolumn{6}{|c|}{ Group UE } \\
\hline A & 1st & $1 \mathrm{st}$ & 3 & 5 & 4 \\
\hline B & - & 2nd & 2 & 3 & 3 \\
\hline $\mathrm{C}$ & - & $3 \mathrm{rd}$ & 1 & 1 & 4 \\
\hline D & 2nd & - & - & 1 & 2 \\
\hline $\bar{E}$ & - & - & - & - & - \\
\hline $\mathrm{F}$ & - & - & - & 一 & - \\
\hline G & - & - & - & - & - \\
\hline $\mathrm{H}$ & - & - & - & - & - \\
\hline I & - & 一 & - & - & - \\
\hline $\mathrm{J}$ & - & - & - & - & - \\
\hline
\end{tabular}

Individual tests. The isolated males (Groups HI and UI) showed the greatest incidence of copulators (Text-fig. 2). No aberrant mounting or other abnormal behaviour was seen. All except one male initiated mounting and all ejaculated by the fourth test session. In contrast, amongst males 
in Groups HE and UE there were only a few copulators, usually the same individuals who had been sexually active in the competitive situation (Table 3); although more males in Group HE than Group UE ejaculated, this effect was not significant. Pair-housed males (Groups HP and UP) showed a level of sexual activity intermediate between that of Groups HI and UI and Groups HE and $\mathrm{UE}$ : frequently only one of the pair was a copulator.

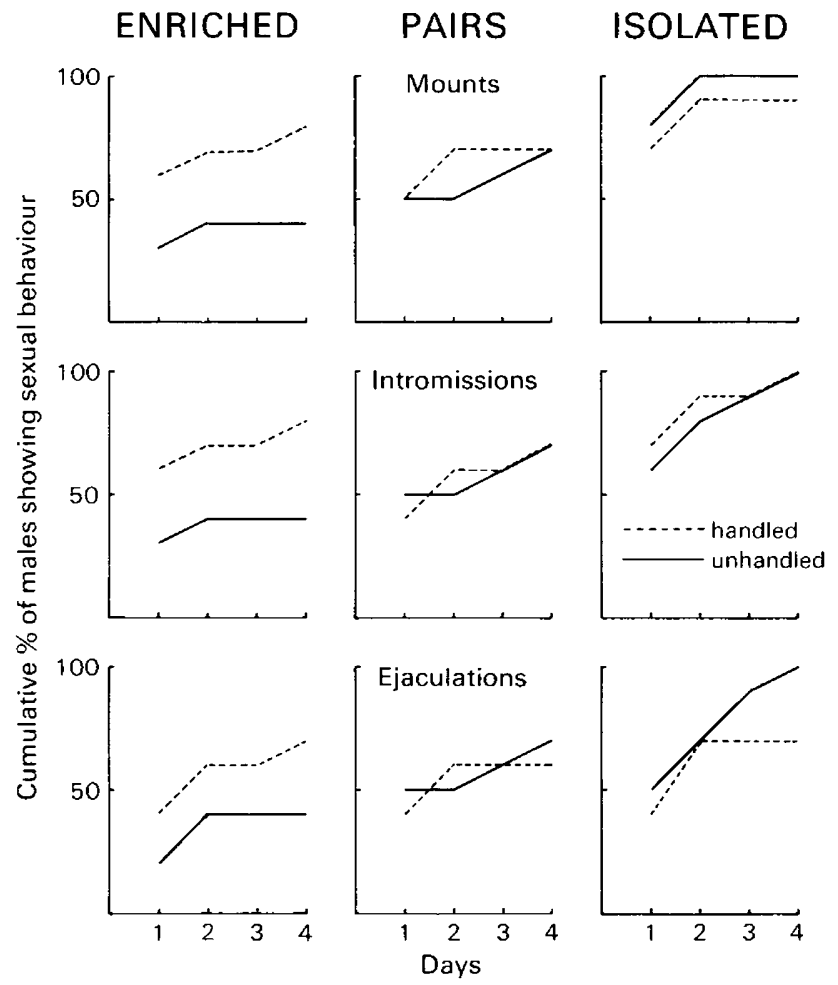

Text-fig. 2. Sexual behaviour of male rats in 4 tests with individual females held on successive days.

At autopsy, there were no significant differences in adrenal, testis or prostate weights attributable to early handling or later environment. The individuals that were dominant in the sexual (and social) hierarchy did not have larger testes or prostate gland, nor were their adrenal weights remarkable.

\section{Discussion}

An unexpected finding was that isolated male rats, far from being sexually incompetent, were the most active copulators. This is in contrast to reports that isolation leads to aberrant mounting with failure to achieve intromission and ejaculation (Gerall et al., 1967; Duffy \& Hendricks, 1973; Spevak et al., 1973; Chambers, Sengstake, Walther \& Bullis, 1982). In earlier studies, however, Beach $(1942,1958)$ found no deficiency in copulatory behaviour of male rats raised in isolation, cohabitation with females or sexual segregation. In the present study a stable sexual hierarchy was seen in groups of 10 males housed together from weaning, insofar as only a few mated with a receptive female placed in their home cage. Moreover, most males that were inactive in the competitive situation also failed to show sexual behaviour when tested individually. In pair-housed 
males, of ten only one of the pair was sexually active. The presence of copulators and non-copulators amongst males housed in group cages as part of normal laboratory husbandry may be due to the establishment of a dominance hierarchy. Gärtner, Döhler \& Rechenberg (1980) observed that, when an oestrous female was placed for 5 min per day for 15 days in a cage containing 4 males, a single individual was sexually most active and also sired most of the offspring.

The observations on social behaviour of juveniles in the present experiment suggest that dominance hierarchies may have been established by play fighting. The peaceful behaviour, good physical condition and lack of variation in adrenal weights in the adult colonies suggests that once a stable hierarchy is established, gregarious animals such as rats no longer find the situation stressful, even with as many as 10 males living together. Sexual hierarchies have also been described in social groups of mice (Bronson, 1979), deermice (Sadleir, 1965), gerbils (Ågren, 1976; Swanson \& Lockley, 1977) and lemmings (Semb-Johanssen, Wiger \& Engh, 1979). Limiting the probability of mating to selected individuals only must have important consequences in population dynamics.

Sexual maturation was delayed in grouped females in an enriched environment. Isolation had the opposite effect. Delayed puberty in socially housed females has been reported for rats (Hansen et al., 1978; Swanson et al., 1983), mice (Vandenbergh, 1973; Drickamer, 1981), gerbils (Swanson \& Lockley, 1977; Swanson \& Payman, 1978; Payman \& Swanson, 1980) and deermice (Sadleir, 1965; Terman, 1968). This inhibition appears to be mediated through pheromones and may play a role in curtailment of numbers in dense populations.

Handling of the young advanced puberty in all three post-weaning housing conditions. Since handled animals weighed more than unhandled at the same age, and body weight at vaginal opening did not differ between groups, the acceleration of puberty may have been a consequence of generally faster development. Improved growth, earlier eye opening and sexual maturation in handled rats have been reported (DeNelsky \& Denenberg, 1967; Levine et al., 1967; Levine \& Thoman, 1970; Villescas et al., 1979). Handling is stressful to young infants as seen by increased corticosteroid production (Levine, 1962; Denenberg, Brugmaghim, Haltmeyer \& Zarrow, 1967). Daily handling for 30 days in the present experiment seemed to constitute long-term stress, since it resulted in adrenal enlargement. The accelerated development of such handled animals suggests that this procedure had a beneficial effect, perhaps analogous to the more adaptive behavioural responses of young handled early in life to a later stressful situation (Levine et al., 1967).

\section{References}

Ågren, G. (1976) Social and territorial behaviour in the Mongolian gerbil (Meriones unguiculatus) under seminatural conditions. Biol. Behav. 1, 267-285.

Beach, F.A. (1942) Comparison of copulatory behavior of male rats raised in isolation, cohabitation and segregation. J. gen. Psychol. 60, 121-136.

Beach, F.A. (1958) Normal sexual behavior in male rats isolated at 14 days of age. J. comp. Physiol. Psychol. 51, 37-38.

Bronson, F.H. (1979) The reproductive ecology of the house mouse. Q. Rev. Biol. 54, 265-299.

Chambers, K.C., Sengstake, C.B., Walther, A.M. \& Bullis, J.E. (1982) Disruption of sexual behavior in socially isolated adult male rats. Behat. Neural Biol. 34, 215-220.

DeNelsky, G.Y. \& Denenberg, V.H. (1967) Infantile stimulation and adult exploratory behaviour in the rat: effects of handling upon visual seeking. Anim. Behav. 15, 568-573.

Denenberg, V.H., Brugmaghim, J.T., Haltmeyer, G.C. \& Zarrow, M.X. (1967) Increased adrenocortical activity in the neonatal rat following handling. Endocrinology 81, 1047-1052.
Drickamer, L.E. (1981) Pheromones, social influences and population regulation in rodents. In Environmental Factors in Mammal Reproduction, pp. 100-111. Eds D. P. Gilmore \& B. Cook. Macmillan, London.

Duffy, J.A. \& Hendricks, S.E. (1973) Influences of social isolation during development on sexual behaviour of the rat. Anim. Learn. Behav. 1, 223-227.

Gärtner, K., Döhler, K. \& Rechenberg, I. (1980) Internal selection and hormonal balance in rat population. Adv. Physiol. Sciences 13, 263-267.

Gerall, H.D., Ward, I.L. \& Gerall, A.A. (1967) Disruption of the male rats sexual behavior induced by social isolation. Anim. Behav. 15, 54-58.

Hansen, S., Larsson, K., Carlsson, S.G. \& Sourander, P. (1978) The development of sexual behavior in the rat, role of preadult nutrition and environmental conditions. Devl Psychobiol. 11, 51-61.

Hård, E. \& Larsson, K. (1968) Dependence of adult mating behavior in male rats on the presence of litter mates in infancy. Brain, Behav. Evol. 1, 405-419.

Hård, E. \& Larsson, K. (1971) Climbing behavior patterns in prepubertal rats. Brain, Behav. Evol. 4, $151-161$. 
Levine, S. (1962) Psychophysiological effects of infantile stiualation. In Roots of Behavior, pp. 246-253. Ed. E. L. Bliss. Harper, New York.

Levine, S. \& Thoman, E.B. (1970) Material factors influencing subsequent adrenocortical activity in offspring. In The Post-Natal Development of Phenotype, pp. 111-122. Eds S. Kazda \& V. H. Denenberg. Butterworths, London.

Levine, S., Haltmeyer, G.C., Karas, G.G. \& Denenberg, V.H. (1967) Physiological and behavioral effects of intantile stimulation. Physiol. Behav. 2, 55-59.

Payman, B.C. \& Swanson, H.H. (1980) Social influences on sexual maturation and breeding in the female Mongolian gerbil (Meriones unguiculatus). Anim. Behav. 28, 528-535.

Sadleir, R.M.F.S. (1965) The relationship between agonistic behaviour and population changes in the deermouse, Peromyscus maniculatus. J. Anim. Ecol. 34, 331-352.

Semb-Johansson, A., Wiger, R. \& Engh, C.E. (1979) Dynamics of freely growing, confined populations of the Norwegian lemming, Lemmus lemmus. Oikos 33, 246-260.

Spevak, A.M., Quadagno, D.M., Knoeppel, D. \& Poggio, J.P. (1973) The effects of isolation on sexual and social behavior in the rat. Behav. Biol. 8, 63-73.

Swanson, H.H. \& Lockley, M.R. (1977) Population growth and social structure of confined colonies of Mongolian gerbils: scent gland size and marking behaviour as indices of social status. Aggr. Behav. 4, 57-89.

Swanson, H.H. \& Payman, B.C. (1978) Social and spatial influences on puberty in the female Mongolian gerbil. In Hormones and Brain Development, pp. 375380. Eds G. Dörner \& M. Kawakami. Elsevier/ North-Holland, Amsterdam.

Swanson, H.H., McConnell, P., Uylings, H.B.M., Van Oyen, H.G. \& van de Poll, N.E. (1983) Interaction between pre-weaning undernutrition and post-weaning environmental enrichment on behaviour and brain development in male and female rats. Behav. Proc. 8, 1-20.

Terman, C.R. (1968) Inhibition of reproductive maturation and function in laboratory populations of prairie deermice: test of pheromone influence. Ecology 49, 1169-1172.

Vandenbergh, J. (1973) Acceleration and inhibition of puberty in female mice by pheromones. $J$. Reprod. Fert. 19, 411-419.

Villescas, R., Zamenhof, S. \& Guthrie, D. (1979) The effects of early stress and undernutrition on the behavior of young adult rats and the correlations between behavioral and brain parameters. Physiol. Behav. 23, 945-954. 